of the Royal Physical Society. As an account of the observations and experiments, which were numerous and detailed, will appear in the next part of the Proc. Roy. Physical Soc, , an indication of their bearing is all that is necessary for the present.

(I) As regards Nosema apis, the authors have been "unable to recognise any causal relation between the presence of this parasite and the disease." Healthy stocks with no signs of disease have been found to be heavily infected by the protozoon, and that over prolonged periods. Numerous stocks have exhibited unmistakable symptoms of Isle of Wight disease, and yet no trace of Nosema has been found in them. This was markedly the case in the Deeside outbreak. Lastly, deliberate infection of a stock with Nosema did nat produce the recagnised symptoms of the disease. "Nosema may be a contributing weakening factor, favouring in certain cases the development of this disease, but we have not found that it is an essential factor."

(2) As regards the infectiousness of Isle of Wight disease : If it be allowed that Nosema, with its readily transported spores, is not the prime cause of the disease, the supporting evidence of infectivity is weakened, and the direct evidences must be examined more critically. The authors have watched in detail the natural course of Isle of Wight disease in three independent localities, and have followed the history of untainted swarms placed in contaminated hives and fed on contaminated honey. They have found no indubitable evidence of the infectiousness of the disease, although the indications seem to be that it is "probably infectious"; but in any case they are assured that it is "not necessarily conveyed by mere contact with contaminated hives or combs, or by feeding upon contaminated stores."

It is a point of some interest and importance that, on account of the unsatisfactory nature of experiments on a small scale in artificial conditions, the above results are based on observations and experiments upon hive bees living in natural conditions.

\section{JAMES Ritchie,}

Edinburgh.

(Hon. Secretary, Royal Physical Society).

REGARDING Dr. J. Ritchie's communication, it would seem well to await the published paper of Messrs. Anderson and Rennie before making detailed remarks. Also, as Dr. Ritchie is not the direct author of the paper, it is inadvisable to bring in a third party. However, it is most surprising, to say the least, to learn that "Isle of Wight" bee disease is not considered to be infectious. How, then, has the disease spread all over Great Britain and most of Ireland during the last ten years? The statement of the noninfectivity of the disease is emphatically inaccurate. Dr. Ritchie writes of the "unmistakable symptoms" of the disease. But, what are the characteristic symptoms? The investigators working under the Board of Agriculture, in their reports of 1912 and I9I3. showed conclusively that there were no well-marked differential symptoms of "Isle of Wight" bee disease. This was also pointed out in my article in NATURE, and the reason for this is obvious, namely, the limited range of expression of the bee, as was also mentioned in my article. Of the workers contributing to the reports of the Board of Agriculture, two were bacteriologists, two were protozoologists, and one was an expert beekeeper. Many field experiments as to the pathogenicity of Nosema apis were conducted, and the investigators were unanimously of the opinion that "Isle of Wight" bee disease is microsporidiosis. Apparently Dr. Ritchie and Messrs. Anderson and Rennie have quite overlooked the importance of parasite carriers, a subject which was carefully pointed out in my article and in the Journal of the Board of Agriculture, Supplements Nos, 8 and ro. Healthy carriers of most parasitic diseases are known.

As to "drastic recommendations," the simple elements of sanitation only were suggested, about which there can be no dispute. The destruction of hives was not suggested in my article. Regarding the experiments of Mr. J. Anderson and Dr. J. Rennie, there is no statement in the above letter as to what stages of Nosema apis were used by them.

These remarks must suffice for the present. My article was written after ten years' personal investigation of "Isle of Wight" bee disease, in nearly every part of Great Britain. Judging from Dr. Ritchie"s letter, the paper of Messrs. Anderson and Rennie appears to contain little but negation.

F.

\section{Preventive Eugenics.}

THE writer of the valuable article in NATURE of April 6, on the report of the Royal Commission on Venereal Diseases, has given it the title of "Preventive Eugenics," a term for which I am responsible, defining it as "the protection of parenthood from the racial poisons," by which latter I mean all such agents as, injuring the individual, injure also the next generation through him, or her, as parent.

Syphilis is, of course, an example of a racial paison, and your writer's protest against the term "hereditary syphilis" is most welcome to one who has made such protests for many years. As Dr. J. W. Ballantyne has said, the term is "an insult to heredity." It indicates the persistent medical and popular blindness to the ante-natal stage of human life. All syphilis is acquired syphilis, an infection of which the date may be ante-natal, when we inexcusably call it "hereditary," or post-natal, when we call it acquired, the fact being too obvious for even the "idols of the forum" to obscure. The Commissioners should have condemned the false term, and used "ante-natal syphilis" instead.

The point is not only academic. Eugenists who have had no medical, much less obstetrical, experience, unaware of the fallacy involved, have assumed much infant mortality to be due to bad heredity, and thus to be an instance of natural selection, when, in fact, ante-natally acquired infection of syphilis was responsible. This grave error is involved in the biometrical publications on infant mortality throughout, and has long discouraged the efforts now being made, at last, to save the infants who are our national future.

Royal Institution, W., April 8.

$$
\text { C. W. Saleeby. }
$$

\section{Atmospheric Electricity.}

IT would be interesting to know if any reader of NATURE has made observations similar to those made here on the afternoon of April i4.

A large thundercloud was just passing off in the east without having produced any obvious thunderstorm phenomena. The sky overhead was occupied by cirrus, while a second thundercloud was coming up in the west. It was found that sparks, one of them certainly reaching 2 or $3 \mathrm{~mm}$. length, could be drawn from the metal of a Besson comb nephoscope, supported on a wooden stand, with the comb at a height of $3 \frac{1}{2}$ metres above an asphalt roof (itself i2 metres above ground), on which observer and nephoscope stood. The leaden roof of a wooden cistern casing yielded similar results, but the most surprising observation was that a Campbell-Stokes sunshine recurder, bolted and cemented to a concrete parapet extending about a metre above the asphalt, also gave 